\title{
Gênero, sexualidade e formação em Educação Física: percepções de professores e alunos em um projeto na escola
}

\author{
Género, sexualidad y formación en Educación Física: percepciones de profesores y alumnos en un proyecto escolar \\ Gender, Sexuality, and training in Physical Education: teachers' and students' perception in a school project
}

\author{
Gustavo de Oliveira Duarte \\ Universidade Federal de Santa Maria, Brasil \\ guto.esef@gmail.com
}

Felipe Barroso de Castro

Universidade Federal de Santa Maria, Brasil

felipecastro99@yahoo.com.br

\author{
Thaiane Bonaldo do Nascimento \\ Universidade Federal de Santa Maria, Brasil \\ thaianebonaldo@yahoo.com.br
}

\section{Resumo:}

Esse estudo objetivou apresentar e discutir as percepções de professores(as) da educação básica, especialmente da área da Educação Física; e alunos(as) (jovens e adolescentes) envolvidos em um projeto que tematizou gênero e sexualidade na escola. Trata-se de uma pesquisa inicial e, portanto, exploratória. Realizamos observações não estruturadas durante as intervenções do projeto nas escolas, pelas quais registramos e analisamos as opiniões, posicionamentos, sentimentos e vivências de professores(as) e alunos(as) sobre os temas gênero e sexualidade. As intervenções do projeto aconteceram em dois momentos: inicialmente de maneira expositiva e, na sequência, por meio de uma roda de conversa, espaço reservado para o diálogo e as discussões. De modo geral, percebemos que os professores pouco haviam abordado as temáticas em sala de aula. Alguns docentes sinalizaram trabalhos quando o tema vem à tona ou em projetos interdisciplinares. Os alunos relataram diversas situações conflitantes no cotidiano da escola e, no geral, emitiram opiniões favoráveis em respeito as diversidades. Consideramos, ao final da investigação, que os temas gênero e sexualidade continuam sendo pouco explorados tanto dentro da escola como nos cursos de formação inicial e continuada de professores de Educação Física, fator que evidencia a necessidade de projetos e iniciativas que levem até a escola essa discussão.

Palavras-Chave: Gênero, Sexualidade, Formação de professores, Escola.

\begin{abstract}
:
This study aims at showing and discussing the perceptions of basic education teachers, especially in the area of Physical Education; and students (youths and teenagers), involved in a Project that thematized gender and sexuality at school. This is an initial research and, therefore, exploratory. Non structural observations were made during the school's Project interventions, in which teachers and students' opinions, placements and experiences about gender and sexuality were recorded and analyzed. The Project interventions took place in two moments: first, in an expository way, followed by a round table conversation, space reserved for dialogues and discussions. Overall, we realized that teachers had barely tackled these themes in class. Some teachers signal works when the topic comes up or in interdisciplinary Projects. Some students reported diverse conflicts on a daily basis at school, and overall, they expressed favorable opinions about diversities. We considered at the end of the research that the topics of gender and sexuality remain poorly explored both inside the school and throughout thePhysical Education teaching training course.
\end{abstract}

KEYWORDS: Gender, Sexuality, Teachers training, School. 


\section{INTRODUÇÃo}

Debater temas como gênero, sexualidade e educação na contemporaneidade é uma demanda vigente, dentro ou fora do espaço escolar. Aliar esse debate a formação de professores(as) e, mais especificamente, a formação em Educação Física sinaliza também o quanto é necessário preparar os(as) novos(as) professores(as) para o trabalho e a tematização desses assuntos na escola. No atual cenário sócio-político brasileiro, somente o estudo, a reflexão, o conhecimento e a conscientização são capazes de fundamentar posicionamentos e argumentos em defesa do respeito as diversidades e, nesse processo, a educação desempenha um papel central.

A base da formação de professores(as) é a formação inicial a qual pode ser entendida como um espaço/tempo em que os(as) futuros(as) docentes têm o primeiro contato com conhecimentos técnicos e pedagógicos, além dos conteúdos e temas de sua área de conhecimento. No entanto, se tomarmos a formação como um processo contínuo e que, portanto, acompanha o(a) professor(a) por toda a sua vida (Nóvoa, 1992) precisamos estar atentos aos debates contemporâneos, sobretudo a partir da formação permanente ou continuada.

No entendimento de Nóvoa (1992), essa característica processual da formação precisa levar em conta o(a) professor(a) como sujeito e, portanto, também como produtor(a) de sua própria formação, na perspectiva de uma autoformação. Nesse sentido, a base da formação inicial é reforçada e adquire subsídios, posteriormente, a partir de uma formação permanente que considera o(a) professor(a) como sujeito de conhecimento próprio, resultante de sua experiência docente e da sua autorreflexão. Esse jogo de pensar e repensar a experiência visa, justamente, na visão de Molina Neto (2014), levar o "conhecimento automatizado pela experiência para o âmbito da consciência [...] na unidualidade professor-investigador" (p. 327).

Nessa direção, acreditamos que o(a) professor(a) precisa dialogar com a realidade e seus diferentes contextos, não somente no que diz respeito a questão macro social, mas também sobre as peculiaridades da realidade em que trabalha. Nesse sentido, muitos são os temas que emergem das realidades escolares e que precisam ser debatidos para apresentar esclarecimentos conceituais e partilhar conhecimento, causa, empatia e respeito no espaço escolar.

Gênero e sexualidade são temas que, muitas vezes, despertam a curiosidade de adolescentes e jovens uma vez que dialogam com os dilemas dessa faixa etária, as mudanças físicas e hormonais, as dúvidas e tensões, um universo a ser explorado. Ao mesmo tempo, é necessário paciência e cautela para que o tratamento pedagógico com esses assuntos alcance os objetivos aos quais os(as) professores(as) se propõem.

Para esse estudo, objetivamos apresentar e discutir as percepções de alguns professores e professoras da educação básica e alunos(as) (jovens e adolescentes) envolvidos em um projeto que tematizou gênero e sexualidade na escola, aliado as discussões da comunidade Lésbicas, Gays, Bissexuais e Transgêneros (LGBT). As intervenções aconteceram em escolas públicas de uma cidade do Estado do Rio Grande do Sul (Brasil) ${ }^{1}$, com uma abordagem que procurou atrair os(as) alunos(as) para a discussão, dando voz aos(as) estudantes.

\section{Opções METODOLÓGicas}

Esse estudo trata-se de uma pesquisa inicial e, portanto, exploratória. Em concordância com Triviños (1987), com esse tipo de pesquisa, busca-se uma primeira aproximação com os temas de estudo nos limites de uma realidade específica. A partir dessa aproximação, complementa o autor, é possível apontar pistas para estudos futuros, bem como delinear especificidades do objeto de estudo em questão.

Como especificam Zamberlan et al (2014), pela sua natureza de sondagem, a pesquisa exploratória é especialmente útil para a abordagem de temas e contextos em que não há muitos conhecimentos acumulados e sistematizados. Em decorrência disso, apresenta aos(as) pesquisadores(as) um planejamento flexível e abre 
possibilidades para cursos alternativos de ação, desenvolvimento de hipóteses e o estabelecimento de critérios e prioridades para pesquisas posteriores.

Nesse cenário, na realidade da rede municipal e estadual de ensino da cidade em que realizamos as intervenções e desenvolvemos essa pesquisa, poucas são as iniciativas pedagógicas para abordar temas como gênero e sexualidade. Do mesmo modo, percebemos ainda uma fragilidade no trabalho com esses temas, inclusive durante os processos de formação inicial e continuada de professores(as). Esses fatores nos levam até a hipótese de que o conhecimento prévio sobre as discussões de gênero e sexualidade tem se dado na escola a partir das influências de outras "instâncias formadoras", quais sejam a mídia, igreja, família; uma vez que a educação formal escolar, aparentemente, pouco aborda essa discussão.

Com a iniciativa do projeto, buscou-se levar até a escola, para professores(as) da educação básica e alunos(as), uma discussão inicial sobre as relações de gênero e sexualidade em meio a outros assuntos em que esses temas podem se mostrar articulados. Portanto, restringimos esses dois perfis de sujeitos participantes dessa pesquisa: alunos(as) (jovens e adolescentes) e professores(as). Um acadêmico de Educação Física, bolsista do projeto, também participou dessas intervenções, contribuindo para a mediação das discussões e com a pesquisa e preparação dos conteúdos e saberes apresentados. A proposta das intervenções aconteceu em um formato expositivo e em rodas de conversa, de uma forma em que não somente os(as) professores(as) e o acadêmico, mas também os(as) estudantes da escola pudessem expor suas opiniões e sentimentos livremente, sem qualquer censura ou desconforto.

Foram escolhidas escolas públicas e turmas com realidades distintas (Ensino fundamental, Ensino Médio e Educação de jovens e adultos), de mantenedoras diferentes (municipais e estaduais) e de regiões da cidade distintas. É importante salientar que das 8 escolas em que houve contato, apenas as 4 participantes dessa pesquisa aceitaram receber o projeto. Isso mostra também o receio que alguns gestores(as) de escola têm para abrir as portas das suas instituições para discussões que envolvam gênero e sexualidade.

Como técnica para a coleta de dados, utilizamo-nos de observações não estruturadas e do tipo participante. Novamente nos valendo da perspectiva de Zamberlan et al (2014), nas observações chamadas não estruturadas, os(as) observadores(as) monitoram os aspectos que se mostram importantes sobre o fenômeno para o problema em foco "tornando-se necessária flexibilidade para identificar os componentes-chave do problema e para formular hipóteses" (p. 119). O tipo "observação participante" denota uma abordagem de observação em que os(as) pesquisadores(as) não são observadores(as) passivos(as), mas podem interagir com os sujeitos da pesquisa e ajudar na mediação das discussões. Os registros dessas discussões foram realizados a partir de um relatório de observação e de fotos e vídeos desses momentos.

A partir da análise desse material, obtivemos diferentes percepções dos sujeitos dessa pesquisa em relação aos temas gênero e sexualidade abordados. Com isso, classificamos as falas, posicionamentos, sentimentos e opiniões a partir de duas categorias: 1 . Alunos(as) e 2. Professores(as) das escolas. No entanto, é importante destacarmos que com a proposta das rodas de conversa, percebemos uma contínua troca de informações e pensamentos, próprias do diálogo e do debate. A sistematização de categorias de análise foi feita apenas para que possamos organizar o discurso dos sujeitos e dos seus "lugares de fala" para que a exposição fique mais adequada nesse texto.

Salientamos que as identidades de todos os sujeitos dessa pesquisa foram preservadas, assim como o nome das escolas que aceitaram receber o projeto e participar dessa pesquisa. Com isso, garantimos o sigilo das pessoas e instituições para não expor aqueles que se propuseram a participar dessa investigação.

\section{GÊnero, Sexualidade E EducaÇão: um desafio contemporâneo}

Incialmente, acreditamos que seja oportuno tratarmos dos significados do conceito de Gênero ao qual nos embasamos a partir de sua perspectiva sociocultural, isto é, apoiado no paradigma das Ciências Sociais e dos aprofundamentos da área da Educação (Louro, 2008). Gênero, nesta perspectiva, refere-se a uma 
organização social baseada na diferença entre os sexos a partir de seu aspecto relacional, (Scott, 1995) isto é, o sentido histórico e crítico do termo é o fio condutor das discussões as quais nos filiamos.

Nesta perspectiva, rejeitamos o determinismo biológico do tema e compreendemos as múltiplas possibilidades do ser-estar feminino e/ou masculino. Isto implica em reconhecer, compreender e respeitar novas e outras construções e arranjos identitários e, consequentemente, sociais, plurais. A categoria de Gênero admite as sociabilidades das identidades subjetivas de homens e de mulheres, no plural. Isto implica em desacomodar nossas velhas certezas, binárias, sobre a tradicional oposição entre homens e mulheres. Desassossega, inquieta, embaralha, mistura e exige, portanto, novos olhares sobre novos fenômenos, novas práticas sociais. Embora haja diferentes linhas teóricas sobre a compreensão dos estudos de Gênero, a nossa filia-se à corrente pós-estruturalista francesa onde Michel Foucault é uma das referências principais.

A partir desta contextualização teórica e pautados na relevância e legitimidade dos Movimentos Sociais no Brasil e no mundo faz-se necessário uma ampliação do olhar acerca do feminino e do masculino como fixos. Nossa aposta é na compreensão de feminilidades e de masculinidades, no plural. E isto faz toda a diferença para que possamos enfrentar diferentes preconceitos e, até mesmo, manifestações de violência simbólica e física sofridas pelos diferentes, esquisitos, estranhos, anormais.

Estudar as relações de Gênero e Sexualidade(s) na Educação e na formação de professores é trabalhar com a ferramenta de desconstrução ao buscar reverter e deslocar uma construção hierárquica entre o significado das coisas compreendidas como naturais (Scott, 1995). Tal postura passa não somente pela formação de professores(as) nas etapas inicial e continuada, na gestão escolar e, sobretudo, nas próprias famílias dos alunos(as) que trabalhamos. É compreender que as relações de poder, de empoderamento, de opressão, de hierarquia fazem parte do complexo jogo ente poderes e saberes. É admitir que não há neutralidade na práxis pedagógica, que mesmo no silêncio há discursos em pontos de vista interligados, levando em consideração cada contexto e suas especificidades. Marcas do corpo, marcas de poder (Louro, 2008). É preciso problematizar as práticas sociais hoje, na contemporaneidade, investigar mesmo o porquê das coisas acontecerem desta ou daquela maneira, sem desmerecer seus atravessamentos históricos. Tal postura "exige dar olhos e ouvidos a muitos aspectos da prática cotidiana da educação escolar que muitas vezes vêm sendo silenciadas" (Pereira \& Assunção, 1997, p.116).

Compreender as contribuições dos Estudos de Gênero é compreender o corpo como um construto biológico, social e moral, de maneira interligada, evitando a fragmentação e a classificação fixa, reducionista. Compreender o corpo de nossos alunos e alunas é atentar para todo o seu cotidiano: a comida, as religiões, as mídias, a indústria da "moda" e da beleza, a classe social, a etnia, entre outros (Soares, 2003). Ou seja, compreender que o corpo não é nunca será neutro, ele é atravessado por diferentes questões de ordem social e cultural e que isto tudo interfere e dialoga com nossas aulas, nossos conteúdos, nossas posições como professor(a) e como pessoa. Meninas de cabelo curto, meninas gordas, meninas bonitas, frágeis, altas demais, baixinhas, cuidadosas; meninos fortes, com atitude, atletas, bagunceiros denotam posturas de gênero, portanto, generificadas. Marcas do corpo, marca de poder.

É no cotidiano e no complexo jogo das relações que se estabelecem entre os grupos, categorias, "guetos" que nascem as representações sociais dos sujeitos que por sua vez acabam por moldar as atitudes e posturas da classe de professores/as. Segundo Pereira e Assunção (1997) a escola é um lugar de rituais, sexistas e religiosos, "e estes estão entranhados de ideologias sociais e culturais que se manifestam em todas as suas atividades, e que acabam por expressar as representações” (p. 119).

Neste sentido, o conceito de gênero não parece adequar-se

“ao desempenho de papéis masculinos e femininos, mas sim ligados à produção de identidades - múltiplas e plurais - de mulheres e homens no interior de relações e práticas sociais (portanto no interior de relações de poder). Essas relações e práticas não apenas constituem instituem os sujeitos (esses vários tipos de homens e mulheres), mas também produzem as formas como as instituições sociais são organizadas e percebidas. Nesse sentido, a escola, como um espaço social que foi se tornando, historicamente, nas sociedades urbanas ocidentais, um locus privilegiado para a formação de meninos e meninas, 
homens e mulheres é, ela própria, um espaço generificado, isto é, um espaço atravessado pelas representações de gênero" (Louro, 1997, p.77).

Frente à complexidade e a necessidade de maior esclarecimento sobre os temas gênero e sexualidade, os processos de formação de professores(as) em Educação Física configuram-se em momentos e espaços propícios para o debate e a problematização desses assuntos. Além de contribuir para a capacitação de acadêmicos(as) e professores(as) já atuantes, a formação pode apontar caminhos para o trabalho com temas emergentes que tanto podem ser desenvolvidos em relação aos conteúdos da Educação Física, como também de forma interdisciplinar.

\section{FormaÇÃo DE Professores(AS): EDUCAÇÃo FísiCA, GÊNEro E SEXUALIDADE EM PAUTA}

Conforme descreve Fensterseifer (2020) a função docente, a educação, o mundo humano e o próprio ser humano são atravessados pela historicidade que lhes é constitutiva, uma vez que se criam, se recriam e se interpenetram. Logo, temos educações e mundos que não são indiferentes aos acontecimentos históricos, as mudanças culturais e as transformações do mundo humano. Entre outras características, destaca o autor, ser professor(a) no mundo contemporâneo é fazer enfrentamentos, é fazer os(as) estudantes "caírem na real", de modo que as identidades destes vão se forjando nessa relação de oposição entre prazer e realidade.

Levando em consideração a amplitude da área da Educação Física, é dever da formação inicial de professores(as) apresentar e discutir temas e debates contemporâneos que, com uma considerável contribuição da mídia e das tecnologias da informação/comunicação do mundo globalizado, são latentes e se manifestam nos mais diversos espaços de nossa sociedade. Isso porque, além dos conteúdos próprios da área, muitos são os temas que podem ser abordados e que "conversam" com outras áreas de conhecimento. É o caso da discussão sobre a mídia e o esporte; uso de doping; lazer, saúde e exercício físico; até discussões sobre preconceitos étnico/raciais, corpo (estética, identidades e diversidade); e mais propriamente o que estamos tratando nesse artigo, gênero e sexualidade.

No Brasil, conforme orienta a Resolução $n^{\circ} 2$, de $1^{\circ}$ de julho de 2015, do Conselho Nacional de Educação (Ministério da Educação), em vigor desde o ano de 2017, é obrigatório que os cursos de nível superior de Pedagogia e Licenciaturas abordem determinados temas em suas matrizes curriculares. Entre outros assuntos como direitos humanos, educação especial e a Língua brasileira de sinais (Libras), está previsto o trabalho com "diversidades étnico-racial, de gênero, sexual, religiosa, de faixa geracional [...]" (Brasil, 2015). No entanto, embora haja esse embasamento legal, nos cursos de Licenciatura em Educação Física, gênero e sexualidade ainda são pouco abordados, conforme diagnosticaram Correia, Devide e Murad (2017).

Em estudo recente de Araújo e Devide (2019), por exemplo, foram analisadas as ementas de diversas disciplinas de cursos de Educação Física Licenciatura em 4 (quatro) universidades públicas do Rio de Janeiro. O objetivo do estudo foi verificar a presença ou não das temáticas gênero e sexualidade e como eram abordados. Após análise, os autores encontraram apenas 4 (quatro) disciplinas que abordavam os temas em questão, sendo que 2 (duas) dessas eram optativas, denunciando a posição de marginalização que essas temáticas se encontram na formação inicial.

Segundo os autores, é nítida a demanda e a necessidade para a discussão desses temas na escola, uma vez que ela é muitas vezes um espaço em que acontecem muitos cenários de discriminação. Nas palavras de Araújo e Devide (2019)

“a falta de conhecimento sobre as temáticas do 'gênero' e da 'sexualidade' impacta a formação desses licenciandos/as de forma negativa, [...] gerando uma falta de sensibilidade dos/as futuros/as docentes sobre como a categoria de gênero influencia os processos de exclusão nas aulas de EFe. Em última instância, essa (in)visibilidade das temáticas impede que licenciandos/as possuam ferramentas para atuarem de forma crítica e reflexiva, colaborando para a naturalização das desigualdades entre meninas e meninos" (Araújo \& Devide, 2019, p.39). 
Já em estudo de Jaeger, Quoos e Venturini (2019), foi analisado a percepção sobre sexualidade de futuros(as) docentes do curso de Educação Física Licenciatura da Universidade Federal do Rio Grande do Sul (UFRGS). A pesquisa inferiu que são raras as disciplinas obrigatórias e/ou optativas do curso que abordam a sexualidade na Educação Física escolar, ademais a compreensão do vocábulo "sexualidade", para a maioria dos(as) participantes(as), apresenta apenas um caráter biologicista. Os conhecimentos e preceitos sobre sexualidade por parte dos(as) acadêmicos(as) foram construídos sob influências fora do currículo, ou seja, a partir da participação em palestras, outros cursos e o próprio convívio social. Para as autoras, portanto, a busca pelo conhecimento sobre essa temática está atrelada às escolhas dos(as) estudantes em suas trajetórias acadêmicas.

Diante dos resultados encontrados, Jaeger et al. (2019) destacam que a formação profissional na área da Educação Física tem um grande desafio em habilitar futuros(as) professores(as) para tratar temas como gênero e sexualidade com clareza e coerência. Isso inclui, justificar a necessidade dessa discussão a favor da educação para a diversidade sexual. No entanto, a reduzida abertura do currículo, seguida da fragilidade das abordagens, podem aumentar o despreparo dos(as) docentes fazendo-os(as) considerar o tema como de abordagem opcional em suas aulas.

A escola se torna um tempo e espaço com grande potencialidade para o debate, uma vez que o assunto transcende a sala de aula, se manifestando nas ações cotidianas da escola. A organização das filas, as roupas e/ ou uniformes escolares, as mensagens nas portas dos banheiros, os apelidos, as práticas de bullying, etc, são alguns exemplos. $\mathrm{Na}$ Educação Física, sobretudo, essas questões podem ganhar ainda mais visibilidade, devido ao seu potencial em problematizar determinações culturais e padróes sociais em torno das práticas corporais e esportivas (Jaeger et al., 2019).

Debatendo esses assuntos, a presença de projetos que abordam pedagogicamente esses temas é de fundamental importância no espaço escolar. Esses momentos tornam-se formativos não somente para os(as) alunos(as) das escolas, mas também para acadêmicos(as) de Educação Física em formação e professores(as) da educação básica que interagem durante as atividades/palestras e repensam suas práticas e intervenções.

\section{Discussão dos Resultados: O PROJETO, AS ESCOlAS E AS PERCEPÇÕes dos SUJEITOS}

O referido projeto foi desenvolvido a partir de Edital público do Observatório de Diretos Humanos $(\mathrm{ODH})$, vinculado à Pró-Reitoria de Extensão da Universidade Federal de origem dos investigadores dessa pesquisa ${ }^{2}$ durante o ano de 2019. O objetivo principal do projeto foi atuar tanto na formação inicial de alunos(as) dos Cursos de Educação Física quanto na formação continuada de professores(as) das redes estadual e municipal de cidade. Houve também um processo de formação específica para um acadêmico(a) bolsista do projeto, discussões formativas em uma disciplina do Curso de Educação Física Licenciatura e, sobretudo, a riqueza das discussóes realizadas em escolas públicas da cidade, objeto de análise principal dessa investigação.

A dinâmica das intervenções foi a mesma para todas as escolas visitadas: primeiramente, uma exposição prévia sobre conceitos de gênero e sexualidade (com ênfase para o corpo e para o movimento), visões do senso comum, acontecimentos, notícias, dados legais em relação a esses temas, aliados também as discussões do movimento LGBT. Para tornar mais atrativa a abordagem, a apresentação de fotos e vídeos foi também um fator fundamental. Durante a exposição, os(as) alunos(as) eram questionados(as) sobre alguns pontos e podiam se manifestar caso se sentissem à vontade para isso.

O segundo momento foi de diálogo e discussão por meio de uma roda de conversa aberta. Alunos(as) e professores(as) puderam expor seu entendimento sobre o assunto, emitir suas opiniões, compartilhando sentimentos e experiências. Todo esse processo foi realizado com cautela, de forma que nenhum desses sujeitos se sentisse constrangido em seu momento de fala ou questionamento.

Foram visitadas 4 escolas, todas situadas no contexto urbano. Identificaremos as escolas a partir da numeração 1, 2, 3 e 4, cada uma com suas peculiaridades e seus limites para o avanço da discussão proposta 
pelo projeto, características que começamos a especificar em seguida. É importante salientarmos também que além da participação de professores(as) de Educação Física das escolas, outros(as) professores(as) de outras áreas do conhecimento também se envolveram nas discussões.

$\mathrm{Na}$ Escola 1 conseguimos reunir 3 turmas de Ensino Médio e apenas uma professora. Percebemos um ambiente aberto para o diálogo e a troca de ideias, embora após a exposição prévia, os(as) alunos(as) mostraram-se tímidos(as) para a roda de conversa. Com poucas falas e posicionamentos, a maioria dos(as) alunos(as) e a professora presente relataram a ausência de casos de pré-conceitos e/ou violência de gênero na escola.

A manifestação mais contundente foi do aluno A que expôs: "eu conheço duas meninas que são gays na escola e eu procuro conviver bem com elas". Em seguida, a professora afirmou que, embora a direção da escola já tivesse abordado o tema anteriormente, mesmo que de maneira simplória, ela ainda não se sentia à vontade para tratar o assunto sem um acompanhamento (referindo-se a iniciativas como a do presente projeto).

Como descrevem Jaeger et al. (2019), essa sensação entre os professores(as) é comum pela falta de familiaridade com o tema, em especial pela sua invisibilidade durante os processos de formação. No entanto, continuam os autores, como gênero e sexualidade estão seguidamente em pauta em nosso dia a dia (debates televisivos, revistas, redes sociais), há maior visibilidade hoje do que a alguns anos atrás o que aumenta nossas possibilidades de abordagem com adolescentes e jovens. Como essas discussões produzem diferentes posicionamentos e condutas, os(as) professores(as) tem sido cada vez mais solicitados(as) para abordar pedagogicamente o assunto em sala de aula.

Cientes dessa necessidade, na escola 1, a coordenação pedagógica e a direção da Escola mostraram-se bastante receptivos para a discussão das temáticas, solicitando, inclusive, um retorno do projeto. A ideia para intervenções futuras é organizar uma proposta diferenciada, visando atender somente os(as) professores(as) como alternativa de formação complementar.

$\mathrm{Na}$ Escola 2 o contexto encontrado foi bem diferente de nossa primeira experiência. Os(as) alunos(as), estudantes do ensino noturno, em sua maioria homens, eram também trabalhadores e, portanto, mais velhos que outros(as) alunos(as) do ensino regular ${ }^{3}$ (em média 17 anos de idade). Participaram da atividade 3 turmas e duas professoras. Durante toda a exposição, a maioria dos(as) alunos(as) mostrou-se ora inquieta, ora impressionada. Percebemos várias manifestações homofóbicas, com o uso de termos pejorativos, posturas de deboche e piadas. Quase todo o momento as professoras precisavam pedir atenção e silêncio aos(as) alunos(as).

Para nossa surpresa, no momento da discussão estes(as) mesmos(as) alunos(as) compartilharam experiências de vida tratadas como marcantes, sobretudo em relação ao tema sexualidade. Questões de gênero a partir de acontecimentos na rotina da própria escola também foram relatados, como na fala da aluna B: "há várias meninas lésbicas na escola e elas sofrem preconceito tanto das meninas quanto dos meninos. Eu vejo elas sempre sozinhas, não interagem bem, sinto pena". As próprias professoras presentes relataram certa surpresa com os relatos dos(as) alunos(as), uma vez que o tema ainda não era abordado em sala de aula.

No contexto das aulas de Educação Física da escola o cenário não se altera, pois embora haja uma aparente invisibilidade dessas questões em aula; elas se tornam latentes nos acontecimentos e nos detalhes que, aparentemente, são notados apenas pelos(as) alunos(as). Esses acontecimentos são potencializados pela própria característica de organização e prática da Educação Física em que, de uma forma ou outra, os(as) alunos(as) precisam "apresentar-se corporalmente" perante os demais. Assim, o alto índice de não participação pelas meninas lésbicas, o medo ou receio nas práticas em que há contato corporal, a dificuldade em se expor ou falar perante a turma; são exemplos do que acontece no cotidiano das aulas de Educação Física e passam despercebidos pelo olhar do(a) professor(a).

Conforme sinalizam Araújo e Devide (2019), abordar alguns elementos como práticas de exclusão, violência, bullying, entre outros, são também alternativas, tanto nas aulas de Educação Física como em outras disciplinas, para se aproximar do tema sexualidade e promover associações, as vezes não tão evidentes para 
alunos(as) e professores(as). Compreendemos, em consonância com Jaeger et al. (2019), que esse debate abre possibilidades para a desnaturalização de padrões e a modificação de comportamentos quando a escola se propõe a ensinar o respeito as diferenças e a importância do convívio harmonioso entre as diversidades.

A Escola 3 ofereceu um tempo e um espaço diferenciados para o projeto. Essa foi a única oportunidade em que não tivemos acesso as turmas para tratar as discussões com alunos(as). Por outro lado, a direção e coordenação pedagógica da escola fizeram questão de que nossa intervenção acontecesse durante o seminário de formação dos(as) professores(as). Com isso, expusemos nosso projeto para cerca de 25 professores(as) de diferentes áreas do conhecimento, além de toda a equipe diretiva.

Diferentemente das escolas anteriores, onde o tempo médio da invenção variou entre uma hora e uma hora e meia, nesta oportunidade, houve a possibilidade de se aprofundar as discussões com um enfoque para a formação dos(as) docentes ao longo de toda uma manhã. Questões como as formas de abordar esses temas em sala de aula, como relaciona-los aos conteúdos disciplinares, alternativas interdisciplinares, ideias para projetos escolares, entre outras iniciativas, foram tratadas sob a mesma perspectiva: exposição do tema e, em seguida, uma roda de conversa.

De uma maneira geral, metade dos(as) professores(as) afirmou já ter abordado questões de gênero e de sexualidade em suas aulas, ainda que não de forma vinculada a conteúdos programáticos, mas de uma forma mais "leve" (adjetivo mais usado pelos professores) quando o assunto apareceu. Alguns(as) docentes, mesmo que demonstrando interesse, não se sentem seguros e decididos para tratar do tema: "não tenho a mínima ideia de como tratar disso em aula" (Professora A).

Da mesma forma, para as duas professoras de Educação Física atuantes na escola a grande questão é por onde começar essa discussão de uma forma que não deixe os(as) alunos(as) constrangidos ou desconfortáveis, fato que na opinião das docentes poderia, inclusive, comprometer ainda mais a participação desses(as) alunas(as) que já vivem uma situação de exclusão. Uma dessas professoras está no início da carreira docente e, desde já, mostra-se como uma referência e liderança no contexto escolar: "Eu estudei algumas questões relacionadas a gênero e sexualidade na formação inicial e pesquisei o tema também na pós-graduação; isso me ajuda na hora de falar sobre" (Professora B).

Quando os(as) alunos(as) tornaram-se o "assunto" da roda de conversa, algumas professoras relataram vários casos de homofobia e de violência simbólica. Quando percebe esse tipo de comportamento, complementa a professora B, "procuro falar disso demonstrando segurança, mas também com simplicidade, temos que tratar eles sempre com respeito e carinho, porque as vezes nem eles sabem”.

Pelo contexto de alguns jovens e adolescentes, atitudes machistas e homofóbicas são tratadas como "normais" e, com isso, se naturalizam em suas ações, tanto na escola como fora dela, influências de uma "heteronormatividade compulsória" como destacam Araújo e Devide (2019). Esse cenário, comumente presente nas escolas, costuma gerar práticas de exclusão e violência, fato também evidente nas aulas de Educação Física complementam os autores.

Percebemos que o grande receio das docentes de Educação Física é perder ainda mais a participação de alguns(as) alunos(as) que possam se sentir expostos(as), embora reconheçam que a tentativa é válida e necessária. A ideia de tematizar práticas corporais que culturalmente foram estabelecidas como masculinas ou femininas foi um ponto de partida levantado pelas professoras, o que poderia dar início a esse trabalho, expondo que dentro do próprio esporte notamos a diversidade de pessoas, corpos, sexualidades.

Notamos, na escola 3, uma abertura para o trabalho com temas contemporâneos e um apoio por parte da equipe diretiva para encorajar os(as) professores(as). Segundo a diretora da escola, referindo-se a discussão de gênero, "este tema está presente dentro da escola e sempre acaba voltando às pautas das reunióes e nós não temos medo de enfrentá-lo". Ao final, o grupo de professores(as) solicitou retorno do projeto para uma intervenção mais direcionada aos(as) alunos(as), explorando as vivências desses(as) estudantes.

Por fim, na Escola 4, o projeto aconteceu com 3 turmas dos anos finais do ensino fundamental e com apenas 2 professores(as) presentes. A intervenção, concidentemente, contribuiu para o amadurecimento de 
um projeto interdisciplinar desenvolvido pela própria escola, o qual estava tratando do movimento feminista e do empoderamento feminino nos dias de hoje, em especial pelas práticas esportivas como o futebol. Em vista disso, os(as) alunos(as) já haviam estudado o tema gênero em algumas disciplinas, o que contribuiu para que, no momento da roda de conversa, a discussão fluísse mais facilmente desde o início.

Os(as) professores(as) participantes expuseram a importância do trabalho com esses assuntos para o combate ao preconceito e para desnaturalizar atitudes machistas. Conforme expôs o professor C, "nós temos dentro da escola e na sociedade como um todo um machismo estrutural, nós nem nos damos conta as vezes que somos preconceituosos, precisamos cuidar nossas falas".

Para Jaeger et al. (2019) esses posicionamentos, ao mesmo tempo que necessários, desafiam continuamente os(as) professores(as) "a negociarem e argumentarem com a comunidade escolar em favor da educação para a diversidade sexual” (p. 78). Não é uma tarefa fácil, salientam as autoras, uma vez que, em algumas escolas, a comunidade cobra dos(as) docentes e da própria escola modos "adequados" de tratar da sexualidade, na tentativa de forçar a escola a pensar a sexualidade dentro dos princípios morais particulares a eles (a comunidade).

Como reiteram as autoras, quando professores(as) ou futuros(as) docentes não possuem aporte teórico para assuntos latentes no âmbito escolar, a exemplo de gênero e sexualidade, corre-se o risco desses sujeitos tratarem as temáticas a partir de seus próprios pressupostos, o que, em certa medida, vai na contramão do que considera Fensterseifer (2020). Para o autor aos(as) professor(as), no "exercício da atividade docente, não lhes são permitidas escolhas pessoais diante de questões que a república normatiza, por exemplo, ser complacente com atitudes racistas ou homofóbicas" (p. 47).

Um dos papéis da educação é justamente tornar visível e esclarecida a diversidade de posições que compõem nossa sociedade, tematizando, desnaturalizando e evidenciando a pluralidade de sentido e significados que os sujeitos podem produzir nos mais variados contextos. Isso não significa, complementa o autor, que a educação pode ser tomada como neutra, uma vez que o ato de educar é político e tem as marcas de nossa intencionalidade pedagógica como professores(as).

Dentro do projeto interdisciplinar da escola, o professor de Educação Física estava desenvolvendo trabalhos sobre a importância e o reconhecimento das mulheres no esporte, em especial no futebol, situando a grande cobertura midiática que a Copa do Mundo de futebol feminino de 2019 estava recebendo no Brasil e no exterior. Para dar suporte a essa discussão, os(as) alunos(as) tiveram acesso a materiais sobre a história do futebol feminino no Brasil, casos de discriminação e personalidades dentro do esporte.

Devido a esse contexto escolar, analisando as falas dos(as) alunos(as) da Escola 4, percebemos que há um esclarecimento um pouco mais elaborado, fruto do papel educativo e de conscientização aos quais a escola está se propondo: "não é por causa que tu é mulher que tu entende menos ou é pior que um homem, tu precisa sempre mostrar se tu é capaz de fazer as coisas e provar que tu sabe, independente de ser homem ou mulher" (Aluna C). Frases como "lugar de mulher é onde ela quiser" foram seguidamente repetidas, em especial pelas meninas da turma do $8^{\circ}$ ano, a qual possui um total de 11 alunos(as) e destes(as), 9 são meninas. Um dos poucos meninos da turma também se manifestou: "eu tenho amigas que são casais gays e a gente se dá bem, acho que temos que respeitar sempre os outros e não julgar".

É notável que essa escola apresenta um contexto favorável ao trabalho com os temas gênero e sexualidade, uma vez que o próprio projeto interdisciplinar da escola tematiza essas questões, o que dá indicativos de que o grupo de professores(as) não mede esforços para abordar temas contemporâneos e latentes. A direção da escola também solicitou retorno do projeto para uma discussão direcionada aos(as) professores(as), o que colaboraria para o amadurecimento do trabalho realizado na escola.

Apesar da fama tradicional e conservadora da região Sul do Brasil, se comparada às demais regiões brasileiras, os(as) professores(as) que tivemos contato mostraram-se muito receptivos(as) em acolher a discussão. Percebemos muita curiosidade e vontade de aprender da maioria dos(as) alunos(as) e também dos(as) docentes, evidenciadas em suas falas, posicionamentos e vivências. 
A maioria dos(as) professores(as) das quatro escolas visitadas afirmaram não ter vivenciado alguma experiência com tais temáticas durante seus cursos de formação inicial, especialmente os(as) professores(as) de Educação Física. Além da professora B, da escola 3, apenas o professor de Educação Física da escola 4 sinalizou algum contato com o assunto, ainda que rapidamente. Percebemos que esse parece ser um fator preponderante para a insegurança quando gênero e sexualidade vêm à tona em sala de aula, fato que não é exclusividade da área da Educação Física, mas de todas as áreas de conhecimento, das linguagens às ciências humanas e exatas.

Frente a essa característica geral não conseguimos explorar falas dos(as) professores(as) que fizessem menção aos seus processos de formação inicial, com exceção da professora B (escola 3), uma vez que gênero e sexualidade ainda parecem estar silenciados e deslocados para as "zonas de sombra" dos currículos como citam Jaeger et al. (2019, p. 82). Mesmo entre os(as) professores(as) mais jovens e que, portanto, estiveram há poucos anos em seus cursos de formação inicial, a situação pouco se modifica.

Embora sejam esses(as) os(as) profissionais mais “esclarecidos(as)" e a par das discussões contemporâneas, o embasamento para o trabalho tem se dado de forma particular através de pesquisas pessoais. Para além de iniciativas próprias, cursos de formação continuada parecem ocupar um espaço complementar na formação, o que evidencia cada vez mais que essa demanda continua vigente.

\section{Considerações Finais}

Refletir sobre debates contemporâneos, a exemplo, das temáticas de gênero e sexualidade na Educação Física é um desafio necessário. É dar voz a questões silenciadas, marginalizadas e instituídas no espaço escolar. Para tanto, os(as) professores(as) necessitam de aporte para abordar esses conteúdos/temas que ainda são tabus societários, o que faz da formação inicial e permanente um tempo/espaço primordial.

A Educação Física é um espaço propício para o debate das questões de gênero e sexualidade quando contribui para a desconstrução de naturalidades e a compreensão da pluralidade das formas de ser. Entretanto, raras são as disciplinas nos cursos de graduação em Educação Física que abordam as temáticas, contribuindo para o despreparo e a insegurança dos(as) futuros(as) professores(as), o que resulta em um silenciamento das discussões no âmbito educacional.

Nessa direção, a necessidade da formação continuada é evidente. Pois, ser professor(a) é estar, sempre, em permanente construção, é avaliar a sua prática, é estar ligado(a) ao mundo, dialogar com a realidade e tornar público o mundo aos(as) estudantes, o que prescinde de estudo contínuo. Para tanto, projetos como o descrito nessa investigação ganham destaque, pois aliam universidade e escola, contribuem na formação inicial de professores(as) e continuada daqueles(as) que já estão atuando no espaço escolar, além de tratar pedagogicamente esses temas com os(as) alunos(as), dando também voz aos(as) estudantes.

É notável que as percepções dos(as) jovens e adolescentes (estudantes) tem sido frutos de suas vivências e opiniões pessoais, influenciadas pela mídia, redes sociais, família, etc. Essas instituições assumem a dianteira uma vez que parece não haver um "lugar" para esse debate, onde houvesse a possibilidade para se produzir esclarecimento e conhecimento. A escola é esse lugar, com múltiplas possibilidades a serem exploradas pedagogicamente.

O projeto demonstrou que refletir sobre gênero e sexualidade na escola e, sobretudo, na área da Educação Física, é uma prática possível e urgente, é demanda contemporânea para formação cultural de nossos(as) alunos(as), sobretudo na realidade brasileira. Sua aceitação no ambiente escolar, os questionamentos de alunos(as) e professores(as) demonstram a necessidade destes assuntos serem abordados com maior ênfase e, sempre que possível, relacionado a realidade social dos(as) estudantes. 


\section{REFERÊNCIAS}

Araújo, A. B. C., y Devide, F. P. (2019). “Gênero" e "Sexualidade” na formação em educação física: uma análise dos cursos de licenciatura das instituições de ensino superior públicas do Rio de Janeiro. Arquivos em Movimento, 15(1), 25-41.

Brasil. Resolução $N^{o}$ 2, de 2015. Define as Diretrizes Curriculares Nacionais para a formação inicial em nível superior (cursos de licenciatura, cursos de formação pedagógica para graduados e cursos de segunda licenciatura) e para a formação continuada. Disponível em: http://portal.mec.gov.br/index.php?option=com_docman\&view=dow nload\&alias=70431-res-cne-cp-002-03072015-pdf\&category_slug=agosto-2017-pdf\&Itemid=30192 Acesso em: 23 mai. 2020.

Correia, M. M.; Devide, F. P. y Murad, M. (2017). Discurso da licenciatura em Educação Física sobre as questões de gênero na formação profissional em Educação Física. En F. P. Devid, Estudos de gênero na educação física e no esporte (pp. 17-48). Curitiba: Appris.

Fensterseifer, P. E. (2020). A tarefa educacional na especificidade da escola. Ijuí: Unijuí.

Jaeger, A., Quoos, M. y Venturini, I. (2019). Imbricações entre sexualidade e Educação Física: desafiando a formação profissional. En R. L. Sawitzki, L. E. Martiny y A. A. Jaeger, Vida, vivência e experiência de professores de Educação Fisica (pp. 69-86). Curitiba: CRV.

Louro, G. L. (1997). Gênero e Magistério: Identidade, História, Representação. En D.B. Catani et al. Docência, Memória e Gênero: estudos sobre formação (pp. 75-84). São Paulo: Escrituras Editora.

Louro, G. L. (2008). Um corpo estranho: ensaios sobre sexualidade e a teoria Queer. Belo Horizonte: Autêntica.

Molina Neto, V. (2014). Formação Permanente. En F. J. González y P. E Fensterseifer (3 Ed), Dicionário Crítico de Educação Fisica (pp. 326-327). Ijuí: Unijuí.

Nóvoa, A. (1992). Os professores e as histórias de suas vidas. En Autor (Ed), Vidas de professores (pp. 14-30). Porto: Porto Editora.

Pereira, L. R. y Assunção, M. M. S. (1997). Gênero e Docência: olhares e interfaces. 1 Seminário Docência, Memória $e$ Gênero. FEUSP/SP. Ed. Plêiade.

Scott, J. (1995). Gênero: uma categoria útil de análise histórica. Educação \& Realidade, 20(2), 71-99.

Soares, C. L. (2003). Apresentação. Pro-Posiçôes. 14(2).

Triviños, A. N. S. (1987). Introdução à pesquisa em ciências sociais - pesquisa qualitativa em educação. São Paulo: Atlas.

Zamberlan, L; Rasia, P. C.; Souza, J. D.Silva de; Grison, A. J.; Gagliardi, A.de Oliveira; Teixeira, E.B.; Drews, G.A.; Vieira, E.P.; Brizolla, M.M.B.; Allebrandt, S. L. (2014). Pesquisas em Ciências Sociais Aplicadas. Ijuí: Unijuí.

\section{Notas}

1 Optamos por manter o nome do projeto, das escolas e da cidade em sigilo para preservar a identidade dos(as) autores(as) desse artigo.

2 Novamente, preservamos o nome do projeto e da universidade para resguardar a identidades dos(as) autores(as) desse artigo.

3 Esses alunos eram estudantes de turmas da Educação de Jovens e Adultos, modalidade de ensino ofertada no Brasil para pessoas que não deram continuidade em seus estudos e para aqueles que não tiveram o acesso ao Ensino Fundamental e/ou Médio na idade apropriada. 